Keywords: RMF, Rotary

Filter, MST, mMST,

Laminated Disk

Retention: Permanent

\title{
Testing of Baseline and Laminated Filter Disks using MST and mMST with a Pilot Scale Rotary Filter
}

D.T. Herman

November 2011

Savannah River National Laboratory

Savannah River Nuclear Solutions, LLC

Aiken, SC 29808

Prepared for the U.S. Department of Energy under contract number DE-AC09-08SR22470.

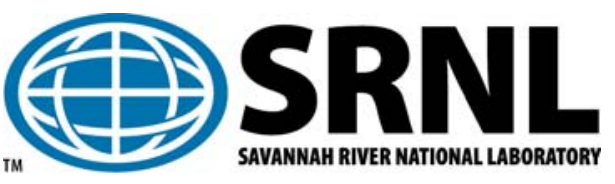




\section{DISCLAIMER}

This work was prepared under an agreement with and funded by the U.S. Government. Neither the U.S. Government or its employees, nor any of its contractors, subcontractors or their employees, makes any express or implied:

1. warranty or assumes any legal liability for the accuracy, completeness, or for the use or results of such use of any information, product, or process disclosed; or

2. representation that such use or results of such use would not infringe privately owned rights; or

3. endorsement or recommendation of any specifically identified commercial product, process, or service.

Any views and opinions of authors expressed in this work do not necessarily state or reflect those of the United States Government, or its contractors, or subcontractors.

\section{Printed in the United States of America \\ Prepared for U.S. Department of Energy}




\section{REVIEWS AND APPROVALS}

\section{AUTHOR}

D.T. Herman

Date

Advanced Characterization and Processing Group

Technical Review

DESIGN CHECK (per E7 2.60)

C.A. Nash

Date

Advanced Characterization and Processing Group

APPROVAL

F.M. Pennebaker, Manager

Date

Advanced Characterization and Processing Group

S.L. Marra, Manager

Date

Environmental \& Chemical Process Technology Research Programs 


\section{ACKNOWLEDGEMENTS}

The author expresses his appreciation to Luay Albakri of SpinTek Filtration for coordinating and conducting the tests described in this report. Thanks to Kathryn Taylor-Pashow for synthesizing the mMST used in this testing. The author would also like to express his appreciation to Bill Greene and Jason Gilmour of SpinTek Filtration for their support and input throughout testing. 


\section{EXECUTIVE SUMMARY}

Testing was completed to compare the filtration performance of modified monosodium titanate (mMST) with that of monosodium titanate (MST) with the rotary microfilter. In addition, the performance of the new laminated filter disk was compared to that of the original baseline welded filter disk. Results showed that flux rates for MMST exceeded that of MST with both the baseline and laminated filter disks in deployment concentrations of $0.2 \mathrm{~g} / \mathrm{L}$ of mMST and $0.4 \mathrm{~g} / \mathrm{L}$ of MST. The filtration rate of the mMST with the laminated filter disk exceeded that of the baseline filter disk. However, the baseline filter disk filtration rate for MST was greater than that of the laminated disk. The measured sample turbidity for all tests was 1.06 NTU or less. 


\section{TABLE OF CONTENTS}

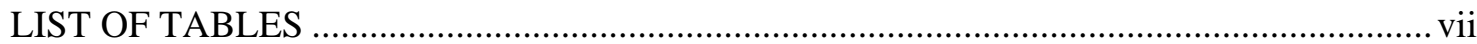

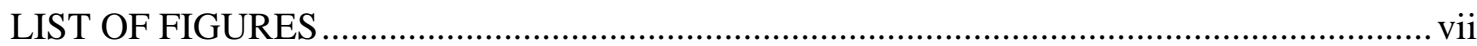

1.0 Introduction

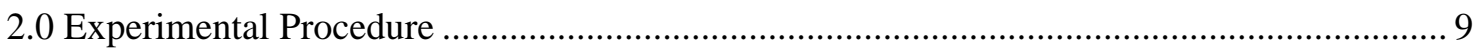

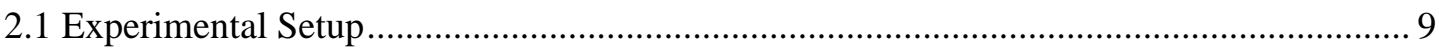

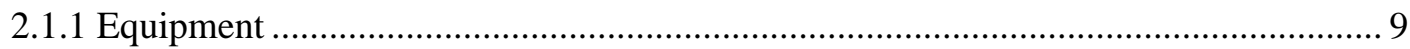

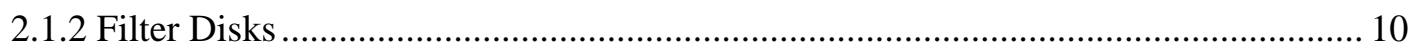

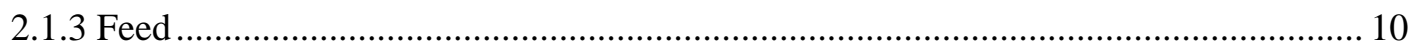

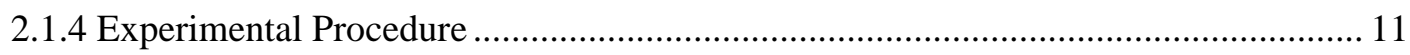

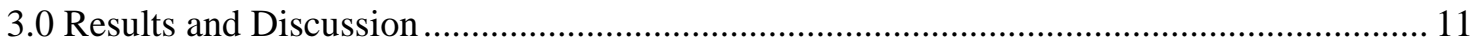

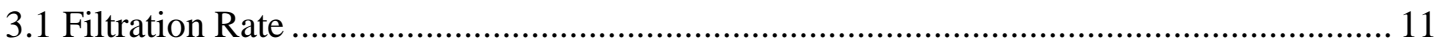

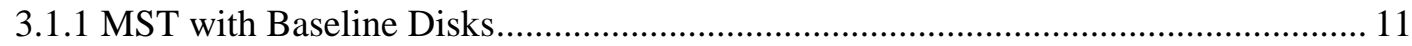

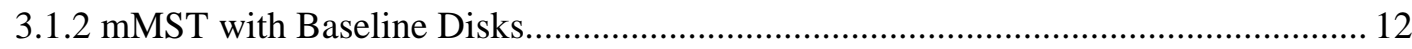

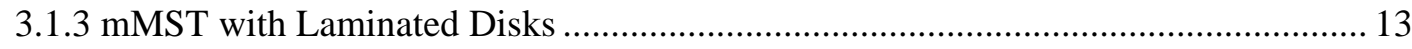

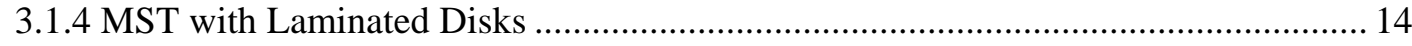

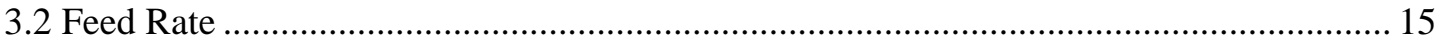

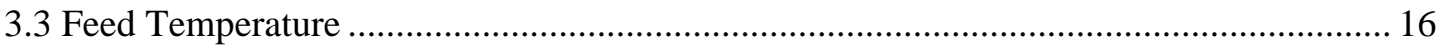

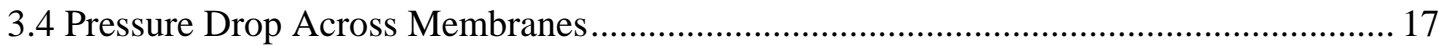

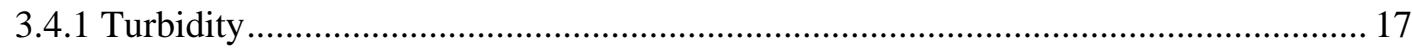

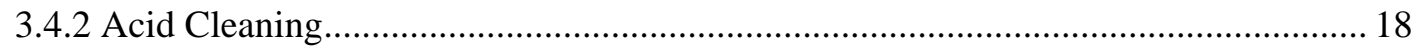

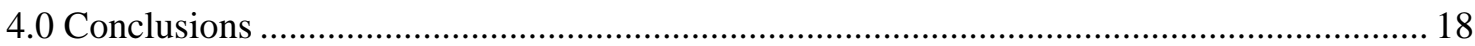

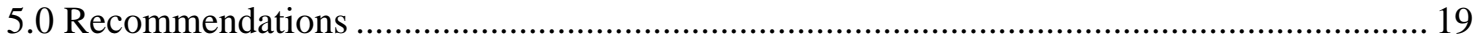

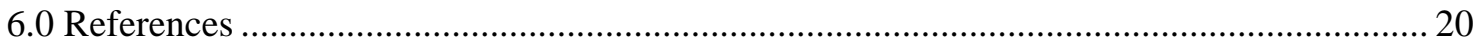




\section{LIST OF TABLES}

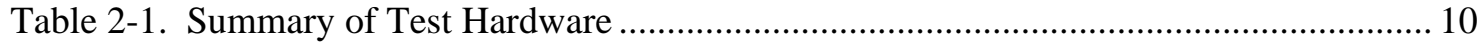

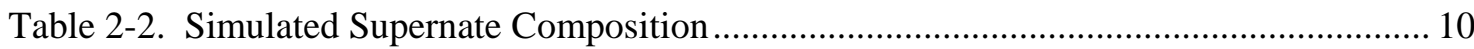

\section{LIST OF FIGURES}

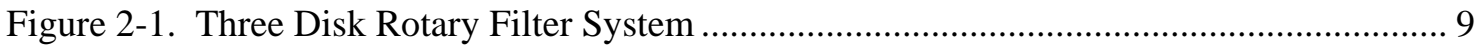

Figure 3-1. Filter Flux for 0.5 micron Baseline Disk with 0.4 g/L MST ................................ 12

Figure 3-2. Filter Flux for $0.4 \mathrm{~g} / \mathrm{L}$ MST, $0.2 \mathrm{~g} / \mathrm{L}$ mMST with 0.5 micron Baseline Disk......... 13

Figure 3-3. Filter Flux for $0.4 \mathrm{~g} / \mathrm{L}$ MST, $0.2 \mathrm{~g} / \mathrm{L}$ mMST with 0.5 micron Baseline Disk and, $0.2 \mathrm{~g} / \mathrm{L}$ mMST with 0.5 micron Laminated Disk ...................................................... 13

Figure 3-4. Filtration Rate for $0.4 \mathrm{~g} / \mathrm{L}$ MST, $0.2 \mathrm{~g} / \mathrm{L}$ mMST with 0.5 micron Baseline Disk and, $0.2 \mathrm{~g} / \mathrm{L}$ mMST, and $0.4 \mathrm{~g} / \mathrm{L}$ MST with 0.5 micron Laminated Disk ................... 14

Figure 3-5. Filtration Rate for $0.4 \mathrm{~g} / \mathrm{L}$ MST, $0.2 \mathrm{~g} / \mathrm{L}$ mMST with 0.5 micron Baseline Disk and, $0.2 \mathrm{~g} / \mathrm{L}$ mMST, and $0.4 \mathrm{~g} / \mathrm{L}$ MST with 0.5 micron Laminated Disk ................... 15

Figure 3-6. System Feed Rates for all Tests ..................................................................... 16

Figure 3-7. System Feed Temperatures for all Tests ............................................................ 16

Figure 3-8. Pressure Drop across Membranes for all Tests................................................... 17

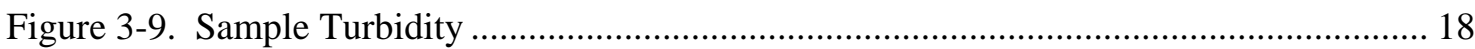




\section{LIST OF ABBREVIATIONS}

$\begin{array}{ll}\text { ARP } & \text { Actinide Removal Process } \\ \text { C } & \text { Celsius } \\ \text { DI } & \text { De-Ionized } \\ \text { F } & \text { Fahrenheit } \\ \text { gpm } & \text { Gallons Per Minute } \\ \text { M } & \text { Molar } \\ \text { mMST } & \text { Modified Monosodium Titanate } \\ \text { MST } & \text { Monosodium Titanate } \\ \text { NTU } & \text { Nephelometric Turbidity Unit } \\ \text { PLC } & \text { Programmable Logic Controller } \\ \text { psi } & \text { Pound per Square Inch } \\ \text { RMF } & \text { Rotary Microfilter } \\ \text { SRNL } & \text { Savannah River National Laboratory }\end{array}$




\subsection{Introduction}

A contract was established with SpinTek Filtration ${ }^{\mathrm{TM}}$ to operate a 3-disk pilot scale unit with prototypic filter disks and various feeds and two different filter disk membranes. SpinTek evaluated a set of the baseline 0.5 micron filter disks as well as a set of laminated filter disks ${ }^{\mathrm{i}}$ using the same 0.5 micron filter disks. The membrane used for both disk sets was manufactured by the Pall Corporation (PMM 050). Each set of disks was run with monosodium titanate (MST) and modified monosodium titanate (mMST). Throughout the testing, samples of the filtrate were collected and measured for turbidity.

\subsection{Experimental Procedure}

\subsection{Experimental Setup}

\subsubsection{Equipment}

Three-disk pilot scale RMF was used in testing with baseline filter disks (edge welded 0.5 micron Pall PMM 050 membrane) and the new laminated disk (sintered disk structure with 0.5 micron Pall PMM 050 membrane). The three disk unit was selected to minimize the amount of feed material required for testing. A photo of the unit is shown as Figure 2-1.

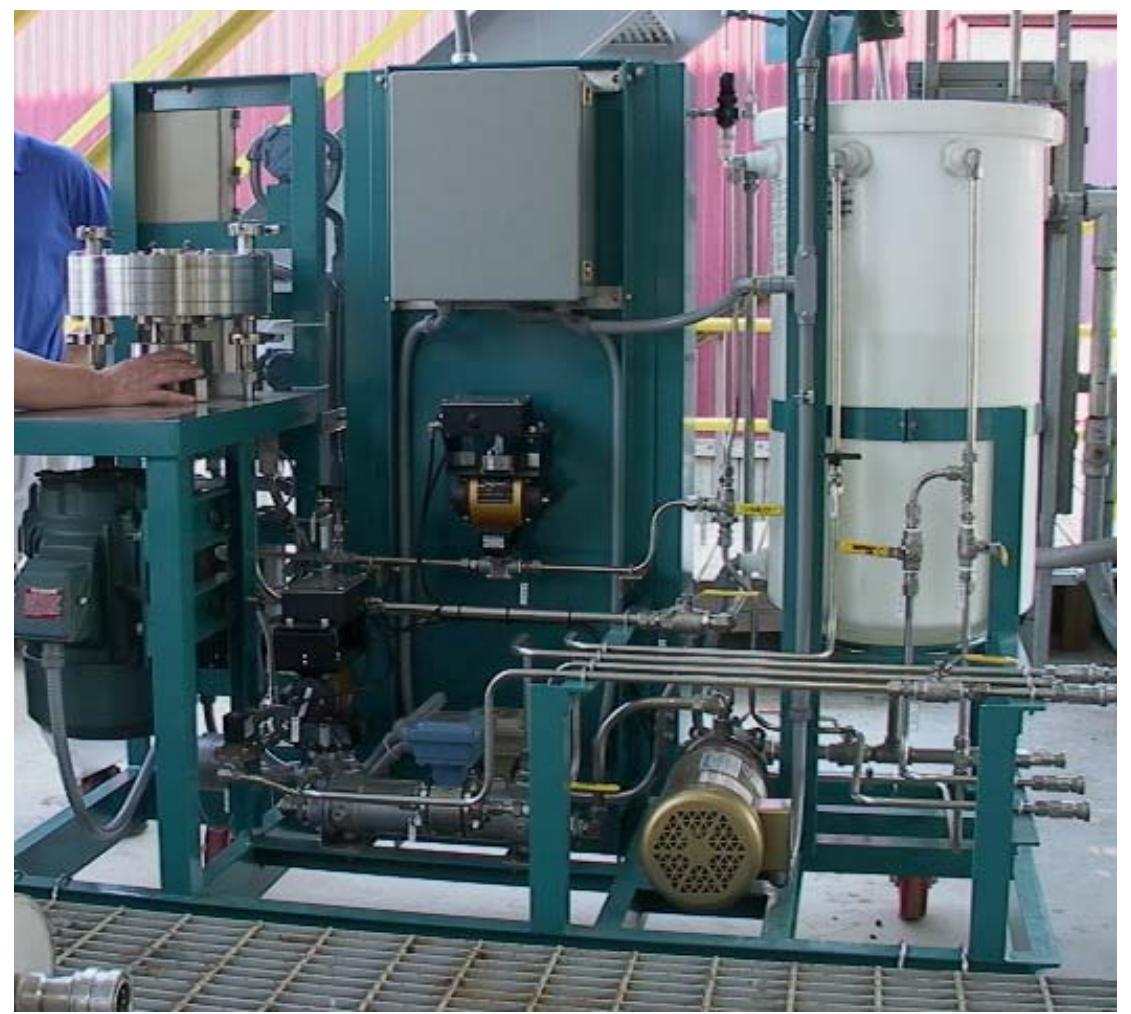

Figure 2-1. Three Disk Rotary Filter System

The system utilizes three full sized disks oriented horizontally. The filter chamber is the stainless steel structure in the upper left hand corner of the photo. A summary of the attributes of the filter used in testing is given in Table 2-1. 
Table 2-1. Summary of Test Hardware

\begin{tabular}{|l|l|}
\hline Pilot filter system \# of filter disks & 3 \\
\hline Filter drive power & $3 \mathrm{HP}$ \\
\hline Baseline filter pore size & $0.5 \mathrm{micron}$ nominal \\
\hline Laminated filter pore size & $0.5 \mathrm{micron}$ nominal prior to lamination \\
\hline Baseline filter disk diameter & $105 / 8$ \\
\hline Laminated filter disk diameter & $105 / 8$ \\
\hline Baseline filter effective area & $0.98 \mathrm{ft}^{2}$ per disk $2.94 \mathrm{ft}^{2}$ for 3 disk pilot filter system \\
\hline Laminated filter effective area & $0.98 \mathrm{ft}^{2}$ per disk $2.94 \mathrm{ft}^{2}$ for 3 disk pilot filter system \\
\hline Filter rotational speed & $1170 \mathrm{rpm}$ \\
\hline
\end{tabular}

The 3 disk pilot scale filter system control logic does not allow for the operation (rotation) of the filter disks without a positive pressure on the filter chamber.

\subsubsection{Filter Disks}

The laminated disk was developed for use with a rotary filter to withstand a reverse pressure and flow eliminating a potential accident scenario that could have resulted in damage to the filter membranes. While the baseline welded filter disks have been shown to withstand and reverse pressure/flow in the static condition, the laminated filter disk allows a reverse pressure/flow while the disks are rotating. This allows for increased flexibility during filter startup and cleaning operations. The laminated disk is manufactured with a more open structure significantly reducing internal flow restrictions in the disk and weighs significantly less that the baseline disk.

\subsubsection{Feed}

Two slurries were used in testing with one containing insoluble solids of MST and the other with insoluble solids of mMST. Each material was used in their respective planned deployment concentration, $0.4 \mathrm{~g} / \mathrm{L}$ for MST and $0.2 \mathrm{~g} / \mathrm{L}$ for mMST. The base salt solution for each slurry was a nominal 5.6 molar (M) sodium salt solution consisting of components as shown in Table 2-2. The salt solution was prepared by SpinTek.

Table 2-2. Simulated Supernate Composition

\begin{tabular}{|c|c|}
\hline Component & Concentration (M) \\
\hline Free $\mathrm{OH}^{-}$ & $1.33 \mathrm{E}+00$ \\
\hline $\mathrm{NaNO}$ & $2.60 \mathrm{E}+00$ \\
\hline $\mathrm{NaAl}(\mathrm{OH})_{4}$ & $4.29 \mathrm{E}-01$ \\
\hline $\mathrm{NaNO}_{2}$ & $1.34 \mathrm{E}-01$ \\
\hline $\mathrm{Na}_{2} \mathrm{SO}_{4}$ & $5.21 \mathrm{E}-01$ \\
\hline $\mathrm{Na}_{2} \mathrm{CO}_{3}$ & $2.60 \mathrm{E}-02$ \\
\hline Total Na & $\mathbf{5 . 6}$ \\
\hline
\end{tabular}

The MST used for the testing was obtained from batches currently used in the Actinide Removal Process (ARP) and was manufactured by Harrell Corporation lot \# 082709. The mMST was synthesized at the Savannah River National Laboratory (SRNL) and identified as Batch LS-11. 


\subsubsection{Experimental Procedure}

The filter operational parameters were targeting the historical running conditions ${ }^{\mathrm{ii}}$ typical of full scale testing. These targets included pressure drop across the membrane of approximately 40 pounds per square inch (psi). Due to the configuration of the three disk rotary filter, the filtrate outlet pressure was at atmospheric pressure (no filtrate backpressure). Feed flow rate was targeted between 5 and 7 gallons per minute (gpm). The feed temperature target was $95 \pm 9{ }^{\circ} \mathrm{F}$ $(35 \pm 5 \mathrm{C})$. The feed temperature was maintained by an external chiller and heat exchanger on the concentrate return line.

The individual tests were conducted for approximately100 hours. The runs were not required to be continuous but all tests concluded without interruption.

The tests were run in the following order:

MST with the baseline 0.5 micron disks

mMST with the baseline 0.5 micron disks

mMST with the laminated disks

MST with the laminated disks

The tests were run in this order due to the availability of the filter disks. The laminated disks were still under construction when the testing started. The tests with the nominal disk were run in consecutive weeks and the laminated disk tests were started $21 / 2$ weeks after the baseline disk tests were completed. Instead of switching the feed back to the MST, the mMST feed was run first with the laminated disks to minimize system cleaning between feeds.

During testing, data was recorded manually and the system was monitored remotely with manual data collection during off-shift hours. Daily filtrate samples were pulled and the turbidity was measured.

\subsection{Results and Discussion}

\subsection{Filtration Rate}

\subsubsection{MST with Baseline Disks}

The first test was completed using the baseline disks with MST at $0.4 \mathrm{~g} / \mathrm{L}$. The filter flux is shown in Figure 3-1. The results were typical for the RMF, with a high initial flux that decayed to lower rate as the filter cake formed. Flux eventually reaches a quasi-steady state where the filter cake is removed as fast as it forms. 
SRNL-STI-2011-00682 Revision 0

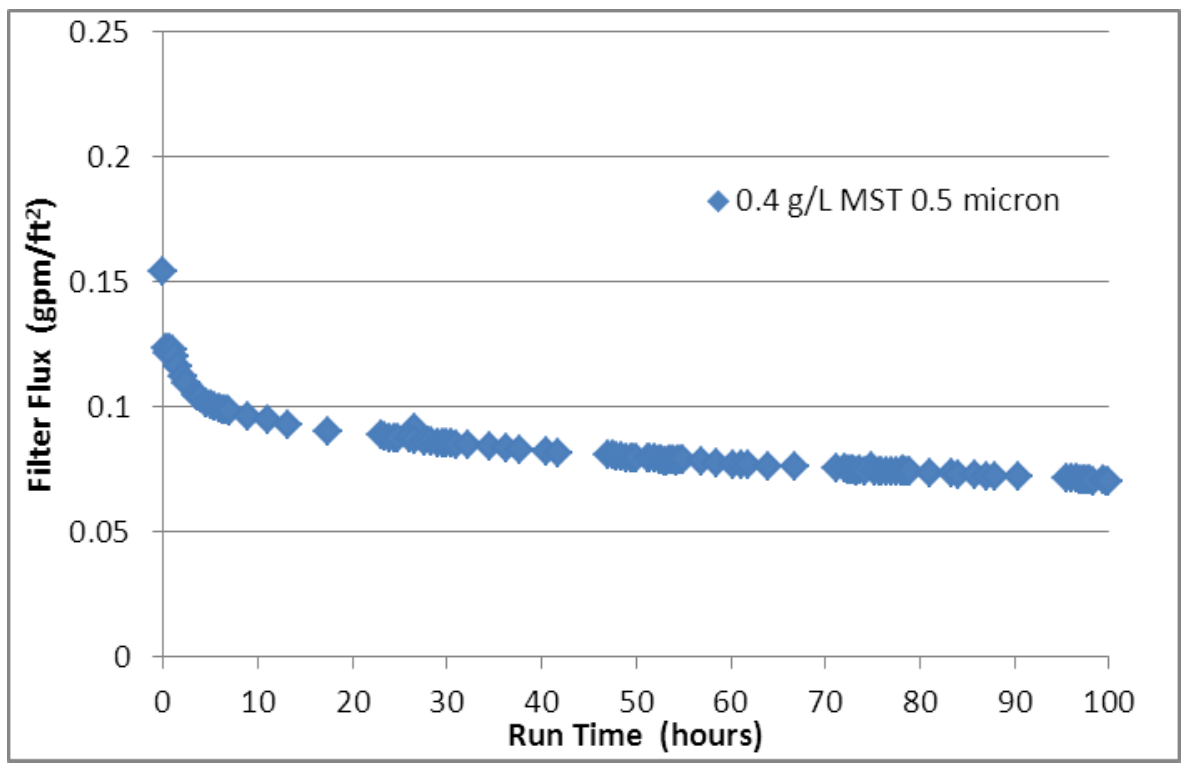

Figure 3-1. Filter Flux for 0.5 micron Baseline Disk with 0.4 g/L MST

The set of filter disks used in this testing had been used in previous testing. ${ }^{\text {iii }}$ The disks were cleaned in $3 \mathrm{M}$ nitric acid at the completion of that testing.

\subsection{2 mMST with Baseline Disks}

After the MST testing with the baseline disks was completed, the filter system was cleaned and the feed was changed to the mMST slurry. Typical cleaning of the disks is described in Section 3.4.2. The baseline disks were then run and the resulting filter flux is shown in Figure 3-2. The filtration rate of the mMST was consistently higher than the filtration rate of the MST. The decay curve for the mMST was also flatter over the 100 hours of operation, in other words, the filtration rate showed less decay over the 100 hours of testing.

In comparing the performance of the MST to the mMST, it must be remembered that the intent of the test was to compare the filtration of the materials at the deployment concentration for the materials. 
SRNL-STI-2011-00682 Revision 0

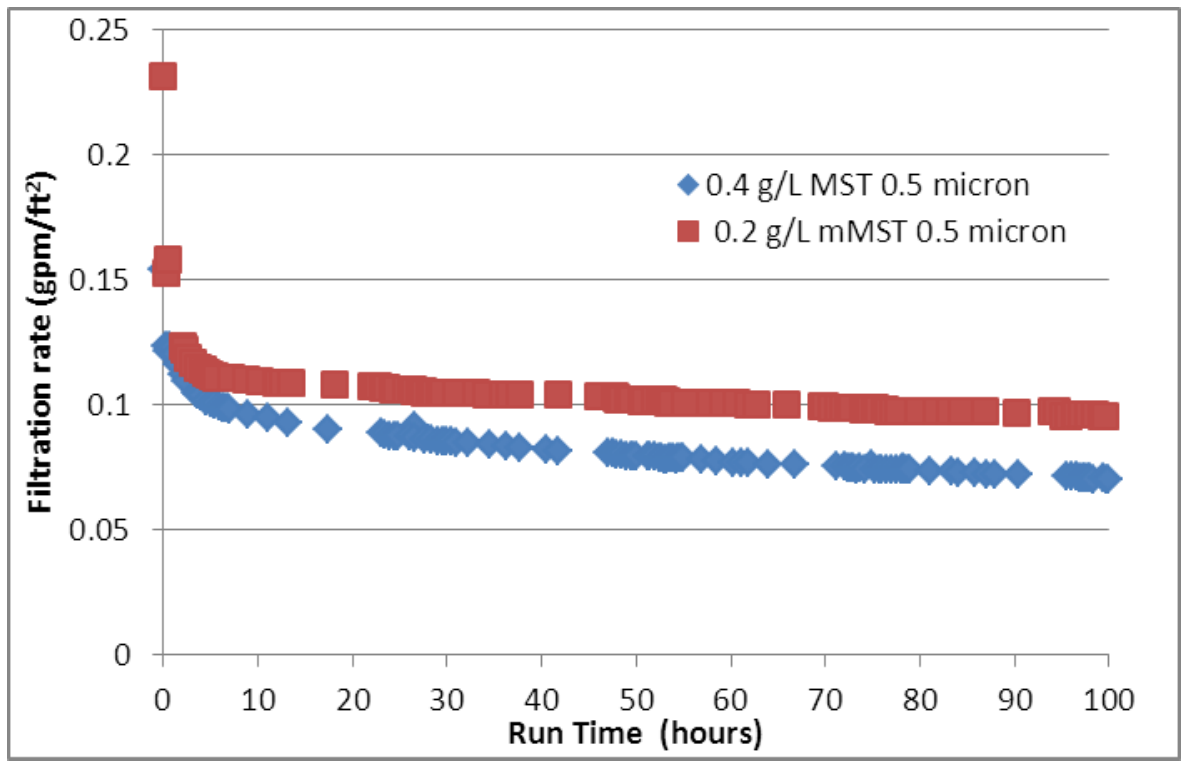

Figure 3-2. Filter Flux for 0.4 g/L MST, 0.2 g/L mMST with 0.5 micron Baseline Disk

\subsection{3 mMST with Laminated Disks}

After testing both slurries with the baseline disks, a set of the new laminated disks were installed. The first feed run was the mMST that was run in the previous test. The resulting filter flux is shown in Figure 3-3.

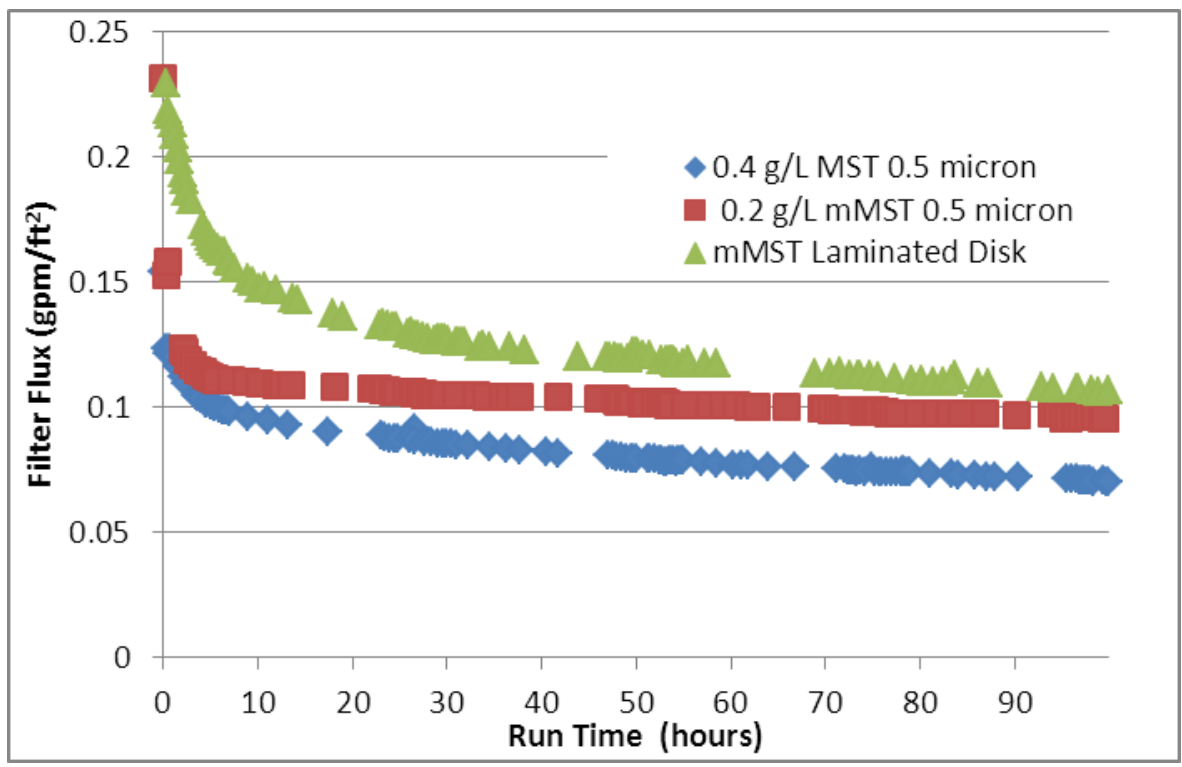

Figure 3-3. Filter Flux for $0.4 \mathrm{~g} / \mathrm{L} \mathrm{MST,} 0.2 \mathrm{~g} / \mathrm{L} \mathrm{mMST}$ with 0.5 micron Baseline Disk and, $0.2 \mathrm{~g} / \mathrm{L}$ mMST with 0.5 micron Laminated Disk

The laminated disks resulted in a higher flux than the baseline disks. Flux increases were over $60 \%$ in the first 10 hours and remained over $11 \%$ after 100 hours. The filtration decay curve shape more closely resembled the filtration curve of the test with the baseline disk and MST. 


\subsubsection{MST with Laminated Disks}

After the completion of the 100 hour test with the laminated disks and mMST, the system was prepared for the test with the laminated disks and MST. For this, the disks were removed and cleaned by soaking overnight in $1 \mathrm{M}$ nitric acid using the same protocol as previous test ${ }^{\mathrm{iii}}$. The system was drained and flushed with de-ionized (DI) water. The same slurry of MST from the first test using the baseline disks was re-introduced to the system and the test was started. The resulting filter flux is shown in Figure 3-4 compared to the results of the previous tests.

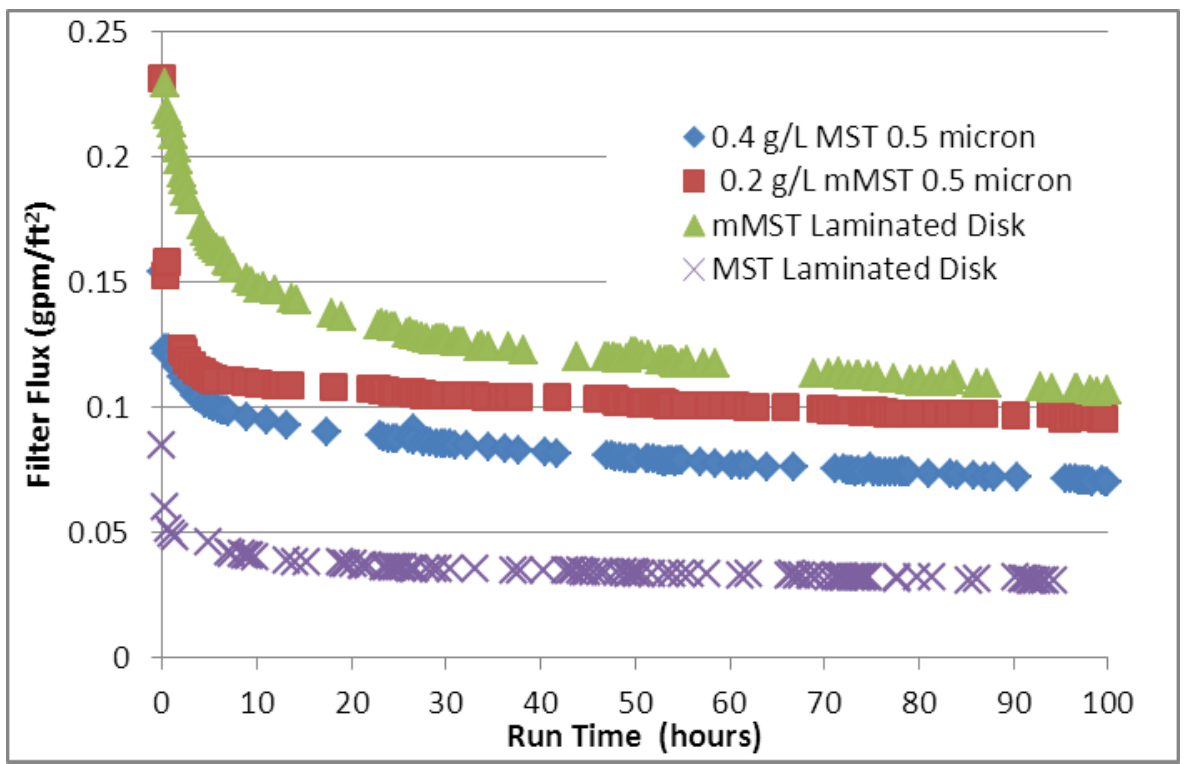

Figure 3-4. Filtration Rate for $0.4 \mathrm{~g} / \mathrm{L}$ MST, $0.2 \mathrm{~g} / \mathrm{L} \mathrm{mMST}$ with 0.5 micron Baseline Disk and, $0.2 \mathrm{~g} / \mathrm{L} \mathrm{mMST}$, and $0.4 \mathrm{~g} / \mathrm{L}$ MST with 0.5 micron Laminated Disk

The filtration rate was surprisingly low. At the end of testing, it was theorized that the filter cleaning was inadequate. SpinTek decided to soak the disks for three days in $1 \mathrm{M}$ nitric acid to allow for additional cleaning. The test was restarted with the same feed and the resulting filter flux for the first 30 hours is shown in Figure 3-5. The filter flux after the additional cleaning was essentially the same as the 100 hour test. 


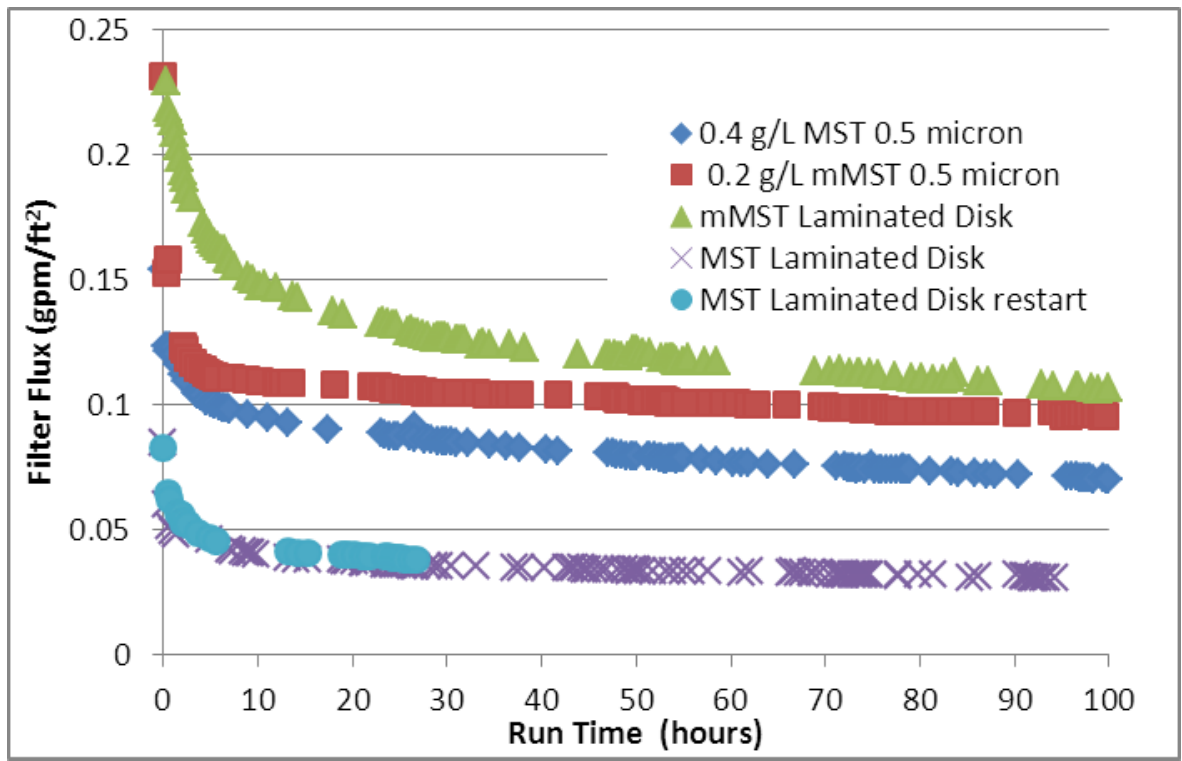

Figure 3-5. Filtration Rate for $0.4 \mathrm{~g} / \mathrm{L} \mathrm{MST,} 0.2 \mathrm{~g} / \mathrm{L} \mathrm{mMST}$ with 0.5 micron Baseline Disk and, $0.2 \mathrm{~g} / \mathrm{L} \mathrm{mMST}$, and $0.4 \mathrm{~g} / \mathrm{L}$ MST with 0.5 micron Laminated Disk

It is believed that the sintering process has changed the pore structure slightly in the Pall PMM 050 membrane. The change in the pore structure is such that it is more susceptible to pore depth fouling due to the particle size of the MST.

\subsection{Feed Rate}

The feed rate was generally around 5.5 gpm for all tests except the tests with the laminated disk running MST. Feed rate was just under $6.5 \mathrm{gpm}$ for the original test and restart. Although there was a noticeable difference in feed and filtration rate, historically, increased feed rate typically has no effect on filtration rate due to additional slurry transport away from the disks. ${ }^{\text {ivv }}$ It is believed the higher feed rate was not the cause for the lower flux. 
SRNL-STI-2011-00682 Revision 0

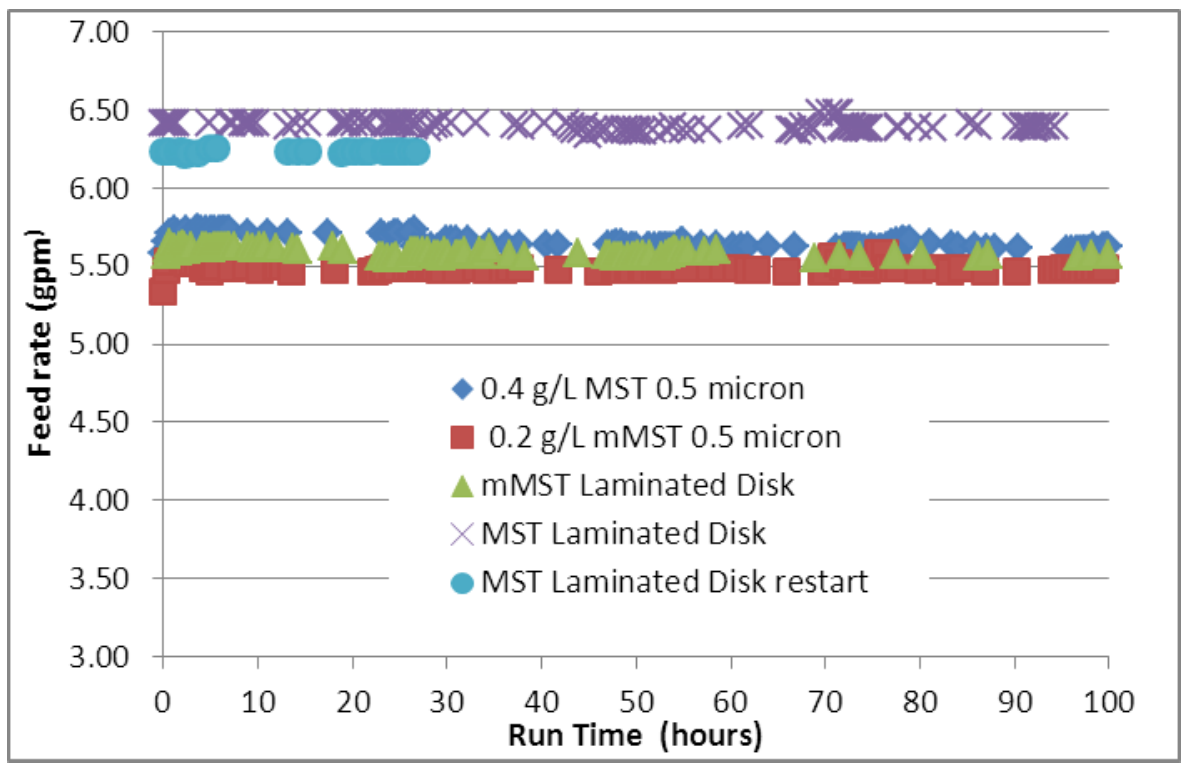

Figure 3-6. System Feed Rates for all Tests

\subsection{Feed Temperature}

Feed temperature was held relatively constant for all tests. The feed temperature for all tests is shown as Figure 3-7. There was a slight increase (less than $5{ }^{\circ} \mathrm{F}$ ) recorded in the system temperature approximately $1 / 2$-way through the test using mMST with the laminated disks that lasted for approximately 6 hours. No change was observed in the filtration rate. Typically, a slight increase in the filtration rate is observed due to changes in bulk fluid viscosity.

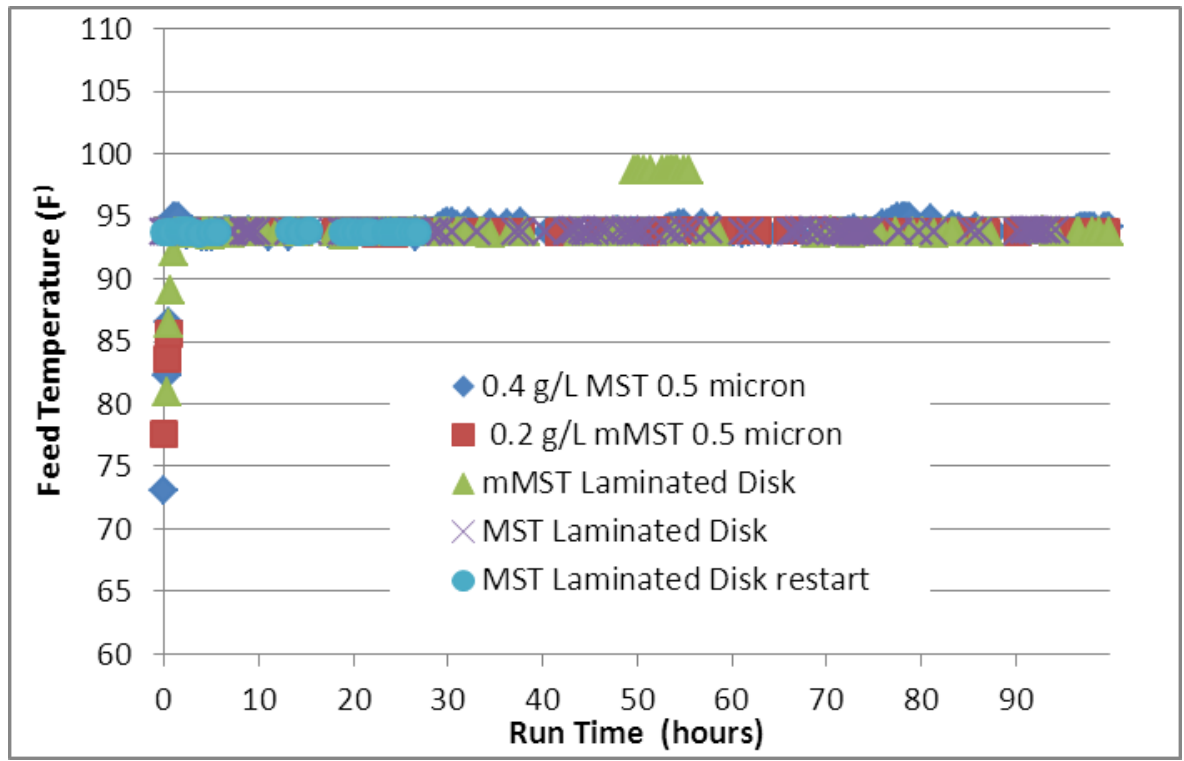

Figure 3-7. System Feed Temperatures for all Tests 


\subsection{Pressure Drop Across Membranes}

The net pressure drop across the membranes is shown as Figure 3-8. Pressure drop was maintained at approximately 40 psi for all tests.

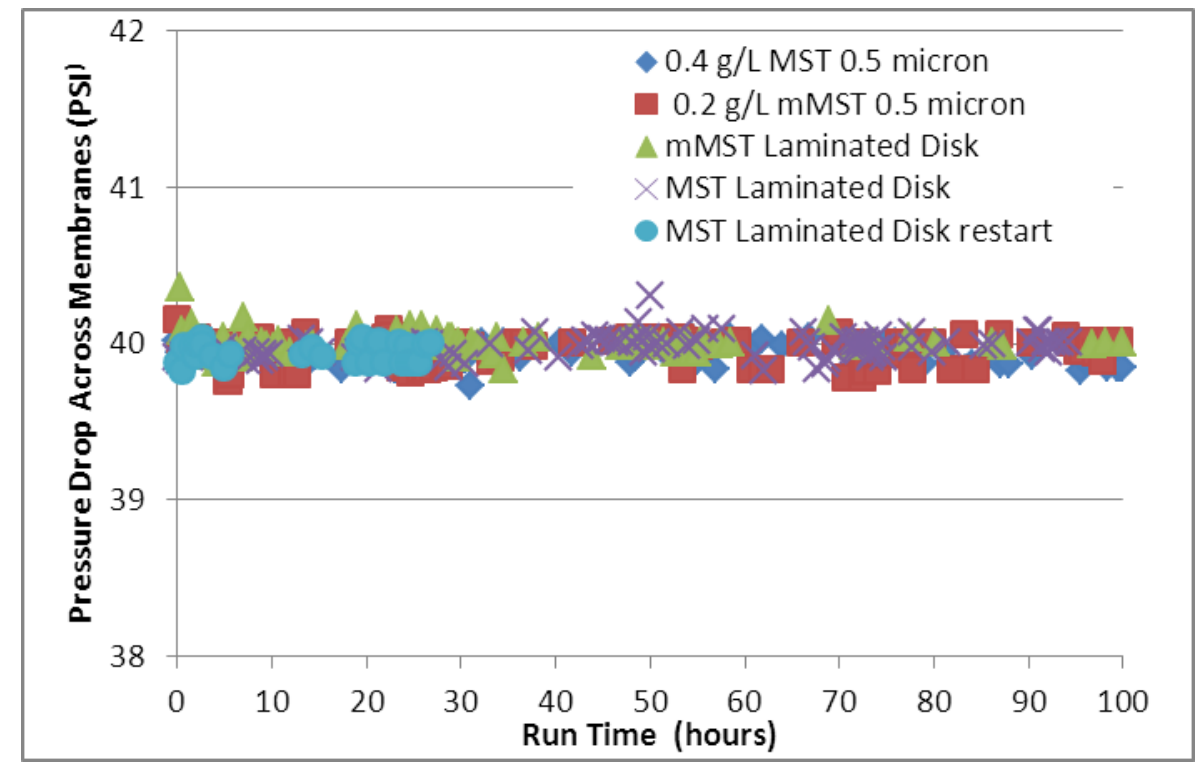

Figure 3-8. Pressure Drop across Membranes for all Tests

The laminated disks were not run without an applied pressure in an attempt to clean the disks and improve filtration rate. Startup of the filter with the laminated disks was accomplished with the historic protocol of starting the feed pump and establishing system pressure prior to operation of the disk rotor. This was due to the programmed logic of the filter programmable logic controller (PLC). The filter was designed for baseline disk operation. Therefore, the PLC was programmed to prevent a reverse pressure/flow from occurring. The PLC logic was not altered to allow the rotor to be started before a minimum pressure is achieved for this testing to allow a direct comparison.

\subsubsection{Turbidity}

Results of the daily turbidity samples are shown in Figure 3-9. The highest turbidity measured from all samples throughout testing was 1.06 Nephelometric Turbidity Unit (NTU). The turbidity of the laminated disks was measured to be less than the baseline disks throughout testing. The baseline disks had higher turbidities at the start of both tests. Turbidity decreased as the tests progressed. This is assumed to be due to the buildup of filter cake or pore fouling essentially resulting in a finer filter. 


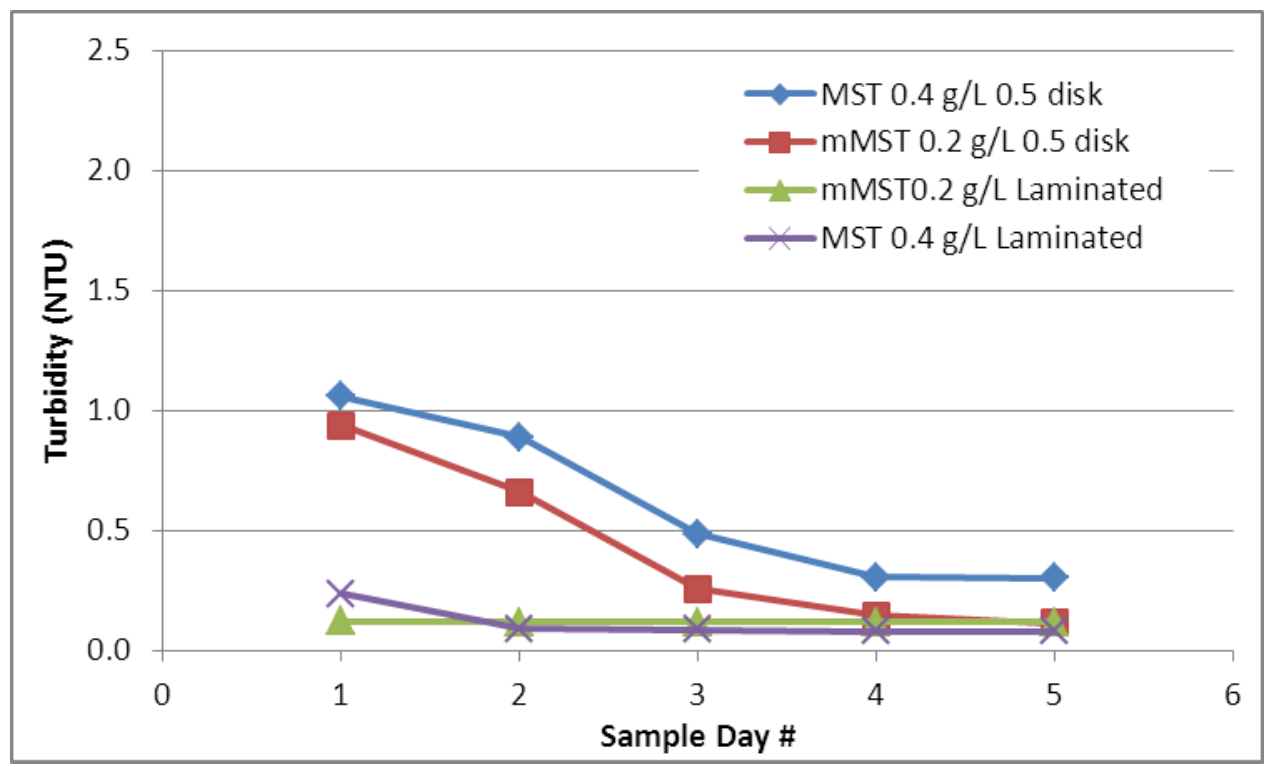

Figure 3-9. Sample Turbidity

Turbidity was measured using a Hach Model $2100 \mathrm{~N}$ turbidity meter. The machine accuracy is $\pm 2 \%$ of reading plus 0.01 NTU from 0 to 1000 NTU and $\pm 5 \%$ of reading from 1000 to 4000 NTU, per the manufacturer. Standards were run prior to sample measurements and are listed below:

- STABICA ® FORMAZIN STANDARD 4000 NTU. Hach Company, Cat.No.2461-02

- STABICA ${ }^{\circledR}$ FORMAZIN STANDARD 1000 NTU. Hach Company, Cat.No.26606-01

- STABICA ® FORMAZIN STANDARD 200 NTU. Hach Company, Cat.No.26604-01

- STABICA ${ }^{\circledR}$ FORMAZIN STANDARD 20 NTU. Hach Company, Cat.No.26601-01

- STABICA ${ }^{\circledR}$ FORMAZIN STANDARD <0.1 NTU. Hach Company, Cat.No.26597-01

All standards read within the reported accuracy of the meter.

\subsubsection{Acid Cleaning}

The filter disk sets were cleaned between each of the tests. The cleaning was accomplished by soaking the disks overnight in $1 \mathrm{M}$ nitric acid and rinsing with de-ionized and distilled water. Cleaning was deemed successful since each following test demonstrated increased initial filtration rate with the exception of the last test using the laminated disks. As discussed previously, the final test produced a low filtration rate. For that test, filtration started at a reasonably high level and rapidly decreased. This indicated that the cleaning was successful. A second attempt at cleaning the filter disks resulted in the exact same behavior.

\subsection{Conclusions}

These test results show that the mMST filtered more rapidly than MST in their respective deployment concentrations for both the baseline and laminated filter disks. The filtration rate of the MST with the laminated disk was lower than expected, which is most due to pore pluggage. Turbidity measurements for all tests were approximately one NTU or less throughout testing. Turbidity for the laminated disks were consistently low throughout testing (less than 0.25 NTU), whereas the baseline disks had higher turbidity in the initial samples and decreased as testing progressed. Final turbidities were approximately 0.3 NTU or less for all samples. 


\subsection{Recommendations}

The results of this testing show the viability of the laminated disk based on performance to date. Additional testing should be completed to demonstrate the potential advantages of starting the rotor at the same time as the pump and in-situ cleaning of the disks. Eliminating the concern of reverse flow through filter disks has the potential for significant operational advantages in field deployment including the elimination of several accident scenarios. The laminated disk should be tested in the full scale (25 filter disks) rotary filter and demonstrated for extended periods of performance. An extended full scale test will demonstrate the maturity of the disk for deployment. 


\subsection{References}

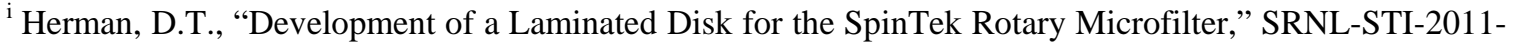
00279, May, 2011.

ii Herman, D.T., “Rotary Filter 1000 Hour Test,” SRNL-STI-2010-00591, September 2010.

iii Herman, D.T., "Rotary Filter Fines Testing for Small Column Ion Exchange,” SRNL-STI-2011-00396, August, 2011.

${ }^{\text {iv }}$ Herman, D.T., Stefanko, D.B., Poirier, M. R., Fink, S.D., “Testing of a Full-Scale Rotary Microfilter for the Enhanced Process for Radionuclides Removal,” SRNL-STI-2009-00183, January, 2009.

${ }^{v}$ Greene, W. A, Kirk, P.A. Hayes, R. Riley, J., “Centrifugal Membrane Filtration Final Report, SpinTek FETC Testing”, Rev. 1, August, 4, 1999.
} 


\section{Distribution:}
A. B. Barnes, 999-W
D. A. Crowley, 773-43A
S. D. Fink, 773-A
B. J. Giddings, 786-5A
C. C. Herman, 999-W
S. L. Marra, 773-A
A. M. Murray, 773-A
F. M. Pennebaker, 773-42A
J. H. Scogin, 773-A
W. R. Wilmarth, 773-A
C. A. Nash, 773-42A
M. R. Poirier, 773-42A
M. D. Fowley, 786-5A 